\title{
Long-term development and effectiveness of private flood mitigation measures: an analysis for the German part of the river Rhine
}

\author{
P. Bubeck ${ }^{1,2}$, W. J. W. Botzen ${ }^{1}$, H. Kreibich ${ }^{2}$, and J. C. J. H. Aerts ${ }^{1}$ \\ ${ }^{1}$ Institute for Environmental Studies (IVM), Faculty of Earth and Life Sciences (FALW), VU University, De Boelelaan 1087, \\ 1081HV Amsterdam, The Netherlands \\ ${ }^{2}$ Helmholtz Centre Potsdam, German Research Centre for Geosciences GFZ, Section Hydrology, Telegrafenberg, \\ 14473 Potsdam, Germany
}

Correspondence to: P. Bubeck (philipb@gfz-potsdam.de)

Received: 20 June 2012 - Accepted: 27 October 2012 - Published: 26 November 2012

\begin{abstract}
Flood mitigation measures implemented by private households have become an important component of contemporary integrated flood risk management in Germany and many other countries. Despite the growing responsibility of private households to contribute to flood damage reduction by means of private flood mitigation measures, knowledge on the long-term development of such measures, which indicates changes in vulnerability over time, and their effectiveness, is still scarce. To gain further insights into the longterm development, current implementation level and effectiveness of private flood mitigation measures, empirical data from 752 flood-prone households along the German part of the Rhine are presented. It is found that four types of flood mitigation measures developed gradually over time among flood-prone households, with severe floods being important triggers for an accelerated implementation. At present, still a large share of respondents has not implemented a single flood mitigation measure, despite the high exposure of the surveyed households to floods. The records of household's flood damage to contents and structure during two consecutive flood events with similar hazard characteristics in 1993 and 1995 show that an improved preparedness of the population led to substantially reduced damage during the latter event. Regarding the efficiency of contemporary integrated flood risk management, it is concluded that additional policies are required in order to further increase the level of preparedness of the flood-prone population. This especially concerns households in areas that are less frequently affected by flood events.
\end{abstract}

\section{Introduction}

In line with a general trend towards more integrated flood risk management approaches, the contribution of private households to flood damage reduction gained increasing importance in Germany, as well as on a European and global level (Laska, 1986; ICPR, 2002; Few, 2003; Federal Environment Agency, 2010; Bubeck et al., 2012a). Complementary to traditional flood protection, such integrated approaches also aim at reducing the potential consequences of floods, amongst others, by means of flood mitigation measures undertaken by private households, such as flood-adapted building use or the deployment of flood barriers. Previous research indicated that these measures are effective in reducing damage and are cost-efficient in many situations (Kreibich et al., 2005; Olfert, 2008; Kreibich et al., 2011a). The cost-efficiency of damage mitigation measures at the household level has also been demonstrated for other natural hazards, such as torrents and snow avalanches (e.g. Holub and Fuchs, 2008; Holub et al., 2012).

In Germany, private households' responsibility for flood damage reduction has been increasingly emphasized and embedded into flood risk management in response to severe floods in 1993 and 1995 along the rivers Rhine and Meuse and in 2002 along the Elbe and Danube (Federal Environment Agency, 2010). Especially the extreme flood in 2002, which caused 21 casualties and more than $€ 11$ billion of economic damage in Germany (Thieken et al., 2006), revealed that significant deficits existed in the regulation and implementation of damage mitigation measures (Petrow et al., 2006) ${ }^{1}$. As a consequence, regulative authority was gradually

\footnotetext{
${ }^{1}$ http://www.bmu.de/english/water_management/doc/36848.php
} 
shifted from the federal states (Bundesländer) to the national government in order to provide more stringent and uniform regulations of spatial planning and damage prevention by households businesses (Federal Environment Agency, 2010). According to $\S 5$ of the German Federal Water Resource Act that was enacted in 2009, every person that could be affected by a flood is obliged to undertake appropriate actions that are reasonable and within one's means to reduce flood impacts and damage (Wasserhaushaltsgesetz, 2009).

However, even though private flood mitigation measures have become an integral component of contemporary flood risk management in Germany and many other countries, knowledge about the latter is still scarce. In particular, the long-term development and the current implementation level of mitigation measures among flood-prone households, as well as their damage-reducing effect are only sporadically known, and such knowledge is often confined to specific regions (e.g. Thieken et al., 2007). For instance, the current implementation level and effectiveness of private flood mitigation measures along the Rhine, which is Europe's largest and economically most important river in Western Europe, has, so far, only been estimated on the basis of expert judgement without a solid empirical basis (ICPR, 2002).

Improved insights into the long-term development of the implementation of flood mitigation measures are important, since a good understanding about changes in past vulnerability is an essential precondition to anticipate the future (John, 1998), for instance, in scenario studies of future flood risks (Hall et al., 2005; Bouwer et al., 2010; te Linde et al., 2011). Moreover, knowledge about the current implementation level and the effectiveness of flood precautionary measures is crucial for assessing the efficiency of contemporary integrated flood risk management approaches and for evaluating the success of flood alleviation schemes. For example, the riparian countries of the Rhine, which cooperate within the International Commission for the Protection of the Rhine (ICPR), adopted the so-called "Rhine Action Plan on Floods" in response to the 1993 and 1995 floods in January 1998. The aim of this flood action plan is to achieve a flood risk reduction of 25 per cent by 2020, compared with the 1995 level. In addition to measures that aim at reducing water levels during times of peak discharges, this risk reduction shall also be achieved through improved damage mitigation by floodprone households (ICPR, 2002, 2006).

The objective of this paper is to better understand the contribution of flood-prone households to contemporary integrated flood risk management by providing insights into the long-term development of the implementation of flood mitigation measures, the current implementation level and their damage-reducing effect. This is done by presenting empirical data from a computer-aided telephone survey among 752 flood-prone households along the German part of the River Rhine. The damage-reducing effect of private flood mitigation measures will be examined by comparing the precautionary behaviour and damage suffered of households that were affected by both the 1993 and 1995 flood events. Such a comparison is of interest, because the hazard characteristics of both flood events were of a comparable magnitude (Engel, 1997). Nevertheless, aggregated damage reported for the 1995 event along the Rhine was substantially lower than in 1993, and it has been repeatedly suggested that this was also due to an improved preparedness (e.g. more damage mitigation measures were in place) of the population affected by the floods (e.g. Engel, 1997; Kron and Thumerer, 2002). A similar conclusion has been drawn for the 1993 and 1995 floods along the Meuse, based on an analysis of aggregated damage data on the community level (Wind et al., 1999). However, it has not been estimated on a household level, yet, whether the difference in damage between the two flood events can indeed be attributed to improved mitigation behaviour. This will be examined in this paper.

The remainder of the article proceeds as follows. Section 2 provides information on the study area, the 1993 and 1995 flood events, and the applied methods. Results are presented in Sect. 3. Section 4 concludes and discusses the implications of our findings for contemporary integrated flood risk management.

\section{Study area and methods}

\subsection{The River Rhine and the floods in 1993 and 1995}

The River Rhine, which flows through Switzerland, Austria, Germany, France and the Netherlands, is one of Western Europe's largest and economically most important rivers. The river basin area of about $195000 \mathrm{~km}^{2}$ comprises nine countries and is home to approximately 58 million people (ICPR, 2001, 2008). The river has undergone severe changes to aid shipping and industrialization, especially since the 19th century; it is nowadays one of the world's most trafficked and used waterways (ICPR, 2008). It connects the European market with the world's largest inland harbour in Duisburg and with one of the world's largest seaports in Rotterdam. Moreover, the Rhine provides water for the cooling of energy plants, and for agricultural, industrial and domestic use (te Linde, 2011). Especially in Germany, major cities and industrial complexes are located on the banks of the Rhine such as Cologne, Bonn or Duisburg or large chemical industries in Ludwigshafen and Leverkusen. According to the ICPR (2001), about 10 million people could be affected by extreme floods along the Rhine.

While floods are a recurring phenomenon along the Rhine during winter and early spring (Chbab, 1995), there were two extreme peak discharge events in 1993 and 1995, with return periods of about $50 \mathrm{yr}$ in its lower reaches (te Linde et al., 2010). Both events led to substantially inundated cities and communities in the lower Rhine and near-flooding and the evacuation of more than 200000 people in the Netherlands (te Linde, 2011). 
In 1993, heavy and persistent rainfall from the 8-18 December had led to highly saturated soils in many parts of the Rhine basin and consequently to impervious land surfaces. During these ten days, almost twice the normal rain quantity was recorded than the long-term mean for all of December in some areas ${ }^{2}$. Therefore, subsequent rainfall that lasted until the 7 January, with a period of torrential rain on 19 and 20 December, was immediately transformed into runoff and led to record discharge levels in many tributaries of the Rhine, such as the Neckar, the Main and the Moselle. The confluence of the flood waves of Rhine and Moselle at Koblenz resulted in one of the highest flood peaks of the lower Rhine ever recorded, with an estimated return period of $45 \mathrm{yr}$ at gauge Lobith (te Linde et al., 2010), which reached the city of Cologne on 24 December with a peak discharge of $10800 \mathrm{~m}^{3} \mathrm{~s}^{-1}$ (Engel, 1997).

Also in 1995, snow melt and heavy precipitation from 1020 January resulted in a sealing of land surfaces (Chbab, 1995). Changing weather conditions from 21 January onwards brought large amounts of rainfall and a sudden increase in temperatures. The combination of heavy precipitation, sealed surfaces and rapid snow melt resulted in fast rising water levels on 23 and 24 January in many tributaries of the Rhine, such as the Main, Nahe and Moselle. The confluence of these flood waves resulted in a flood peak in the lower Rhine that reached the same water level as during the recorded maximum in the 20th century at Cologne in 1926, with an estimated return period of $55 \mathrm{yr}$ at gauge Lobith (te Linde et al., 2010). The flood peak reached the city of Cologne on 30 January 1995 with peak discharge of $11000 \mathrm{~m}^{3} \mathrm{~s}^{-1}$. At $10.69 \mathrm{~m}$, the water level in Cologne was $6 \mathrm{~cm}$ higher than during the 1993 event. As a consequence, inundation levels in Cologne and further downstream in Germany were slightly higher in 1995 . Flood duration was also slightly longer in 1995 (Engel, 1997).

Both floods caused substantial economic damage in the middle and lower reaches of the Rhine. In Koblenz, nearly one quarter of the built-up area was flooded in 1993, affecting approximately 10000 residents. In Cologne, about 4000 people were directly affected during the 1993 and 1995 events. Even though the 1995 flood showed slightly higher water levels and a longer duration (Engel, 1997), reported damage was substantially lower than in 1993. While economic damage was estimated at about $€ 767$ million for the entire German Rhine basin during the 1993 event, damage for the 1995 event was estimated at about $€ 256$ million (Engel, $1997)^{3}$. The same damage pattern was reported for the city of Cologne, which was heavily affected by both events. Even though water levels were slightly higher in 1995, damage in

\footnotetext{
2 http://undine.bafg.de/servlet/is/13872/

3 This has been computed using a Deutsche Mark-Euro exchange rate of 1.95583 .
}

1995 was substantially lower ( $€ 33$ million) compared with 1993 (€56 million) ( $^{4}$

The fact that damage in 1995 was less than half of the amount in 1993 has been repeatedly attributed to an improved preparedness of the population (e.g. Engel, 1997; Kron and Thumerer, 2002). It has been argued that the population at risk took flood warnings more seriously in 1995 and paid more attention to flood preparedness. Consequently, many flood-prone households had undertaken flood mitigation measures and, for instance, had removed their belongings to levels even higher than 1993 water levels. Moreover, households had replaced their oil tanks with gas heating, thereby reducing contamination of flood waters and consequently damage. The reasoning that an improved preparedness of the population reduced flood damage in 1995 has also been put forward by Wind et al. (1999), who examined the 1993 and 1995 flood events and resulting damage on an aggregated level of communities along the Meuse.

\subsection{Survey description, samples and methods}

To gain insights into the long-term development of flood mitigation measures, their current implementation level and their effectiveness, 752 computer-aided telephone interviews with flood-prone households were carried out by the Umfragezentrum Bonn of the Rheinische Friedrich-WilhelmsUniversität Bonn in May and June 2011. The response rate during the main survey was 83 per cent. Flood-prone households along the Rhine were identified by means of aerial photographs of past flood events (BFG, 1995), stakeholder information such as the ICPR, ${ }^{5}$ and flood hazard maps (ICPR, 2001). The thus derived household sample lives in highly flood-prone areas (mainly along the middle and lower Rhine), which is exemplified by the fact that 64 per cent of the households had experienced at least one flood, and 87 per cent of the respondents live in areas that have actually been flooded in recent decades.

In addition to questions about flood experience, risk perceptions and socio-economic characteristics, respondents were asked for the damage that they suffered to contents and building structure during the two most severe flood events they had experienced. Moreover, it was elicited whether respondents had implemented different types of flood mitigation measures and when they did so. A more detailed description of the survey and the sample characteristics is found in Bubeck et al. (2012b).

To examine the damage-reducing effect of flood mitigation measures, damage to contents and structure in 1993 and 1995 are visually compared by means of box and whisker plots, which depict the distribution of the damage data. To assess whether damage and water levels of respondents dif-

\footnotetext{
${ }^{4}$ http://www.koeln-altstadt.de/altstadt/rheinhochwasserinkoeln/ hochwasser1993inkoeln/index.html

5 A. Schmidt-Breton (ICPR), personal communication, March 2011.
} 


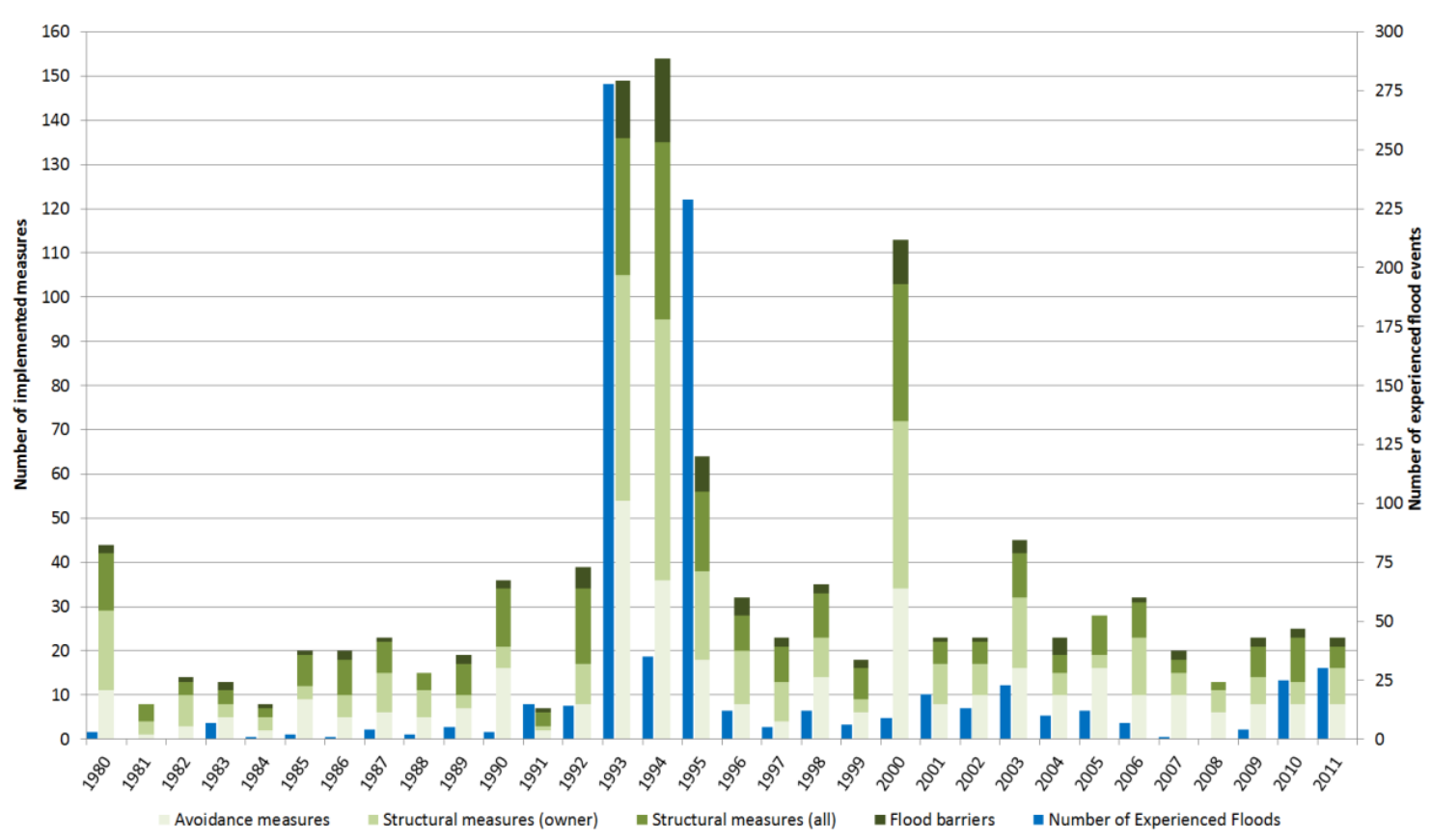

Fig. 1. Long-term development of the implementation of four types of flood mitigation measures by flood-prone households $(n=752)$ along the German part of the Rhine.

fered in 1993 and 1995 at statistically significant levels, the Wilcoxon signed-rank test was applied (Wilcoxon, 1945). The Wilcoxon signed-rank test is a test statistic to compare two sets of scores (paired difference test) that come from the same participants (a repeated measure design) and can be considered as the non-parametric equivalent of the dependent t-test (Field, 2009). To account for the non-parametric distribution of the data, it is based on a ranking of the data instead of the actual numerical data. Whether there is a central tendency between the two observations is examined by comparing the mean ranks of the two conditions (Wilcoxon, 1945), for instance between damage to contents in 1993 and 1995. The high skewness of the damage data is also the reason why no mean damage values are reported in the results section. Instead, medians as well as z- and p-values of the Wilcoxon signed-rank test are reported. Moreover, effect sizes (r-values) are provided.

\section{Results and discussion}

\subsection{Long-term development and the current implementation level of flood mitigation measures among flood-prone households}

Figure 1 provides an overview on the flood events that the respondents experienced as most severe, as well as the longterm development of four different types of flood mitigation measures among flood-prone households between 1980 and 2011: namely, structural measures implemented by home- owners, structural measures implemented by owners and tenants, avoidance measures and flood barriers. The distinction between structural measures for owners and structural measures for both owners and tenants is made because some of these measures, such as improving building stability, can only be carried out by owners. Other structural measures, such as deploying a back-flow protection device to the sewer, can be implemented by both owners and tenants.

Figure 1 clearly indicates that the 1993 and 1995 events have been the dominant flood events experienced by the surveyed households. While 278 respondents indicated that the 1993 flood belonged to the two most severe flood events they had experienced, 229 respondents did so for the 1995 flood. Also the recent flood in the beginning of January 2011, which flooded among other places parts of the city of Koblenz, was mentioned by 30 respondents. In terms of implemented flood mitigation measures, Fig. 1 shows that all four types were deployed gradually over time, with major flood events being important triggers for an accelerated implementation. Especially in the aftermath of the severe floods in 1993, a remarkable increase in the number of undertaken measures can be observed for all four types. Despite the severity of the 1995 flood, the level of implementation remained relatively low afterwards. Since the 1995 flood inundated similar areas as in 1993, it can be assumed that the level of preparedness was already high in the aftermath of the 1993 event, and, therefore, did not increase that much afterwards. That flood experience strongly influences the adoption of precautionary measures is also confirmed by correlation analyses. The 
number of reported flood events per year shows a strong correlation with the number of implemented measures (Cohen, 1994). The correlation coefficients range from $r=0.52$ for structural measures up to $r=0.67$ for avoidance measures. These findings are in line with previous studies, which also observed that (flood) hazard experience is an important influential factor on precautionary behaviour (Weinstein, 1989; Kreibich et al., 2009, 2011b; Bubeck et al., 2012c). Thieken et al. (2007) for instance, report correlation coefficients ranging from 0.28 to 0.30 between flood experience and mitigation behaviour.

However, Fig. 1 and the correlation analyses also indicate that experience is an important, but not the only factor influencing flood mitigation behaviour. For instance, a peak in the implementation of measures can be observed in 2000 without pronounced flood experiences indicated by the respondents. A likely explanation for this peak is the so-called Whitsun flood that affected the upper Rhine, and especially the Danube river catchments, which caused substantial economic damage (Kron, 2004). While this event did not result in a direct flood experience among the respondents, it again illustrated the potentially detrimental impacts of flood events after the 1993 and 1995 events. A possible additional explanation for the peak in 2000 is that there have been considerable mobilisation efforts among flood-prone households on behalf of the Hochwassernotgemeinschaft Rhein e.V. ${ }^{6}$. This is an association of cities, communities and civil-society organisations along the middle and lower Rhine, which conducted four workshops in Germany in Cologne, Koblenz, Speyer and Karlsruhe in 2000 in cooperation with the ICPR (ICPR, 2005) to emphasize the need for precautionary behaviour. These workshops were attended by about 600 participants, ${ }^{7}$ and, according to the ICPR, raised awareness among far more people via media reports and multiplication effects (ICPR, 2005). However, a direct relation between these mobilization efforts and an increase in the implementation of flood mitigation measures could not be confirmed by our data.

Bubeck et al. (2012b) examined a range of factors other than experience that possibly influence flood-precautionary behaviour among flood-prone households along the Rhine. They find that for the implementation of structural measures, which are associated with substantial financial costs (Kreibich et al., 2011a), income plays an important role. Moreover, flood-coping appraisals, the social environment and non-protective responses are a significant influence on different types of flood mitigation behaviour. Flood-coping appraisals refer to the respondent's estimate of the effectiveness of a certain measure and whether he or she feels capable of actually undertaking it (Rogers and Prentice-Dunn, 1997). The social environment captures whether neighbours

\footnotetext{
6 www.hochwassernotgemeinschaft-rhein.de

7 A. Schmidt-Breton (ICPR), personal communication, May 2012
}

or friends also undertook a measure. The positive relation with precautionary behaviour shows that people are strongly influenced by the behaviour of others. A negative influence on flood precautionary behaviour is found for non-protective responses. Non-protective responses, such as wishful thinking or denial, do not actually reduce the risk of perceived flood risk, but help to avoid or supress the negative emotions associated with it (Festinger, 1957).

A detailed picture of the current implementation level of various flood mitigation measures, split by tenants and homeowners, is provided in Table 1. As can be seen from Table 1, flood mitigation measures are frequently deployed by those at high risk of flooding, especially by homeowners. 56 per cent of the homeowners and 36 per cent of the tenants implemented at least one flood-mitigation measure. That homeowners implement more measures than tenants is consistent with previous studies (e.g. Thieken et al., 2007; Bubeck et al., 2012c). This is due to the fact that a considerable amount of damage is inflicted to the building structure, which is paid by owners. Moreover, tenants are usually restricted in their ability to implement flood mitigation measures independently, because they usually need approval from the owner when installing structural flood protection measures (Grothmann and Reusswig, 2006). Measures that are particularly popular among the households at risk are avoidance measures as well as structural measures, while the deployment of flood barriers is less common (see Table 1).

That a large share of tenants and homeowners did not undertake any flood mitigation measure raises the question whether households understand their high vulnerability to floods. To examine the household's perceived flood risk and to compare it to the perceived risk of other potentially damage-causing events, respondents were asked to rate the likelihood of suffering damage to their property due to several risks of daily life, on a scale from 0 to 10 . A rating of zero indicates that it is very unlikely that the respective event will cause damage to the respondent's property, while a rating of 10 indicates that it is very likely that the event will do so. Table 2 shows that flood risk perceptions of the respondents are high, with a mean rating of above 6 and a median rating of 7. Moreover, it is shown that respondents consider it as much more likely that their property will be damaged by a flood event compared with other risks of daily life, such as burglary, fire in their house or the occurrence of a traffic accident. These figures demonstrate that the surveyed households are aware of their high vulnerability to floods. Possible reasons why high risk perceptions do not necessarily translate into protective behaviour, such as a lack of floodcoping appraisals of an individual, are discussed by Bubeck et al. (2012c).

The considerable share of respondents being unprepared could, furthermore, also result from the fact that respondents are insufficiently aware of their responsibility to contribute to damage prevention in contemporary flood risk management, or, do not agree with it. To examine the households' 
Table 1. Current implementation level of various flood mitigation measures among house owners $(n=457)$ and tenants $(n=295)$ along the Rhine.

\begin{tabular}{lrr}
\hline Type of flood mitigation measure & Owners (\%) & Tenants (\%) \\
\hline Relocate heating system to avoid contamination (str.)* & 33 & n.a.* \\
Replace oil heating system to avoid contamination (str.) & 24 & n.a.** \\
Improve building stability (str.) & 24 & n.a.** \\
Use of flood resistant materials (str.) & 22 & n.a.** \\
Secure oil tank to prevent contamination (str.) & 8 & 6 \\
Install a back flow protection system (str.) & 31 & 17 \\
Avoid expensive fixed interior in flood-prone storeys (avoid.)* & 30 & 22 \\
Avoid expensive items in flood-prone storeys (avoid.) & 36 & 29 \\
Deploy fixed or mobile flood barriers (barr.)* & 19 & 13 \\
Purchase a flood insurance policy & 28 & 18 \\
At least one measure implemented & 56 & 36 \\
\hline
\end{tabular}

$*$ : str. = structural measure, avoid. = avoidance measure, barr. = flood barrier. $* *$ : n.a. stands for not applicable. This type of measure was elicited for homeowners only, because it can not usually be carried out by tenants.

Table 2. Respondent's ratings of the perceived likelihood that several harmful events cause damage to their property $(n=187$ to 194).

\begin{tabular}{lrrr}
\hline $\begin{array}{l}\text { Damage-causing } \\
\text { event }\end{array}$ & Mean & Median & $\begin{array}{r}\text { Standard } \\
\text { deviation }\end{array}$ \\
\hline Burglary & 5.1 & 5.0 & 2.7 \\
Fire in the house & 3.8 & 3.0 & 2.7 \\
Flood & 6.3 & 7.0 & 3.0 \\
Storm & 3.9 & 4.0 & 2.5 \\
Terrorist attack & 1.4 & 0.0 & 2.2 \\
Traffic accident & 3.1 & 2.0 & 3.0 \\
\hline
\end{tabular}

perceived responsibility to contribute to flood damage reduction, respondents were also asked whether they agree with the statement that "households in areas at risk of flooding are responsible themselves to undertake measures to avoid flood damages". While 45 per cent of the respondents $(n=737)$ agreed and 28 per cent rather agreed with this statement, 14 per cent of the respondents did rather not agree or indicated to not agree (11 per cent). Fifty-five (55) per cent of the respondents $(n=742)$ agreed with the statement that "to prevent floods and to cope with possible flood damage is primarily a task of the government." Moreover, respondents were asked whether they are aware of any changes in flood risk management policies. Twenty-nine (29) per cent of the respondents indicated that they are not aware of any changes $(n=695)$. Those aware of a change in flood risk management policies were further asked for the direction of these changes. About 15 per cent of the respondents indicated that the damage and risk associated with flood events would be increasingly covered by governmental authorities. These figures reveal that a considerable share of highly flood-prone households in Germany are not aware, or, do not support their increased responsibility in contemporary flood risk manage- ment. This can serve as an explanation for the low level of preparedness of a large share of the homeowners and tenants.

\subsection{Effectiveness of flood mitigation measures: a comparison between the 1993 and the 1995 flood event}

Figure 1 clearly illustrates that the preparedness of the population significantly increased in the aftermath of the 1993 flood event. This raises the question whether flood damage among households was significantly lower during the 1995 event, and whether a change in damage can indeed be attributed to this improved preparedness of the population. To examine these aspects, a sub-sample $(n=160)$ was derived from the overall sample, which consisted only of those respondents that were affected both in 1993 and 1995. In accordance with Fig. 1, the number of implemented floodmitigation measures increased considerably between 1993 and 1995 also for this sub-sample. In total, the number of implemented measures more than doubled from 212 before the 1993 event to 437 before the 1995 flood (Table 3).

The distribution of reported damage to contents and building structure for both events is depicted in Fig. $2 a$ and b. Both box and whisker plots show that the median damage to contents and structure was higher in 1993 (median $^{\text {content }}=$ $1000 /$ median $\left.^{\text {structure }}=1500\right)$ than in $1995\left(\right.$ median $^{\text {content }}=$ $0 /$ median $^{\text {structure }}=1000$ ). Also the interquartile ranges show higher upper limits for both damage to contents and structure in 1993 and a larger variation. The same holds true for the upper quartile, which shows again that a higher upper limit of damage exists in 1993, which has a larger variation. Moreover, damage cases considered as outliers are higher in 1993 than in 1995. In conclusion, Fig. 2a and b indicate that households suffered higher flood damage to contents and structure during the 1993 flood event compared with 1995. The Wilcoxon signed-rank test confirms that damage to content $(z=-5.832, p<0.001, r=-0.37)$ and structure 

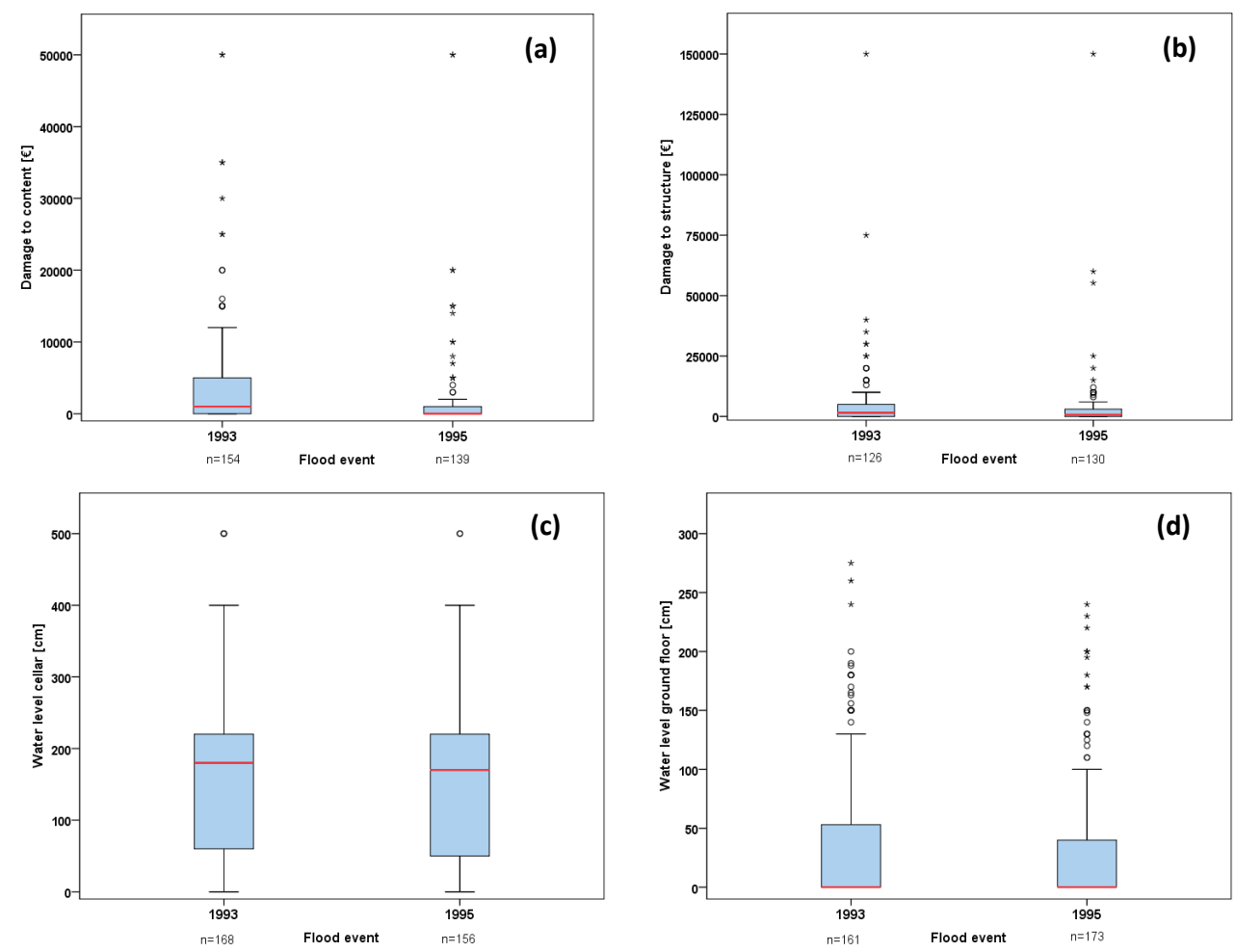

Fig. 2. Box whisker plots of (a) damage to contents, (b) damage to structure, (c) the water level in the cellar, and (d) the water level in the ground floor. Note that damage to contents, damage to structure, water levels in cellar and ground floor are significantly different (Wilcoxon signed-rank test) at the 1 per cent level.

Table 3. Number of total measures implemented by households before the flood in 1993 and the flood in $1995(n=160)$.

\begin{tabular}{lrr}
\hline Flood mitigation measure & 1993 & 1995 \\
\hline Relocate heating system to avoid contamination (str.)* & 20 & 47 \\
Replace oil heating system to avoid contamination (str.) & 13 & 33 \\
Improve building stability (str.) & 12 & 25 \\
Use of flood resistant materials (str.) & 13 & 31 \\
Secure oil tank to prevent contamination (str.) & 12 & 20 \\
Install a back flow protection system (str.) & 39 & 58 \\
Avoid expensive fixed interior in flood-prone storeys (avoid.)* & 25 & 56 \\
Avoid expensive items in flood-prone storeys (avoid.) & 41 & 81 \\
Deploy fixed or mobile flood barriers (barr.)* & 9 & 32 \\
Total number of measures & 212 & 437 \\
\hline
\end{tabular}

*: str. $=$ structural measure, avoid. $=$ avoidance measure, barr. $=$ flood barrier.

$(z=-4.219, p<0.001 ; r=-0.27)$ was lower in 1995 at statistically significant levels. The damage-reducing effect was stronger for damage to contents as to building structures. Since inundation depth was identified as a dominant factor of influence on flood damage (Thieken et al., 2005), households were also compared in terms of water levels experienced in 1993 and 1995. The distributions of reported water levels in the cellar and ground floor during 1993 and 1995 are depicted in Fig. 2c and d. The box and whisker diagram displaying the water level in the cellar (2c) reveals that water levels were similar during both events, with a slightly higher median water level in 1993 (median $^{1993}=$ $180 \mathrm{~cm} /$ median $\left.^{1995}=170 \mathrm{~cm}\right)$. Also the upper limits of the upper quartile and the lower quartile are slightly higher in 1993, while the upper limit of the interquartile range is the same for both events. A similar observation, but slightly more pronounced, holds true for water levels on the ground floor (Fig. 2d), which are higher in 1993. In summary, Fig. 2c and d show that households experienced slightly higher water levels in the cellar and ground floor during the 1993 flood 

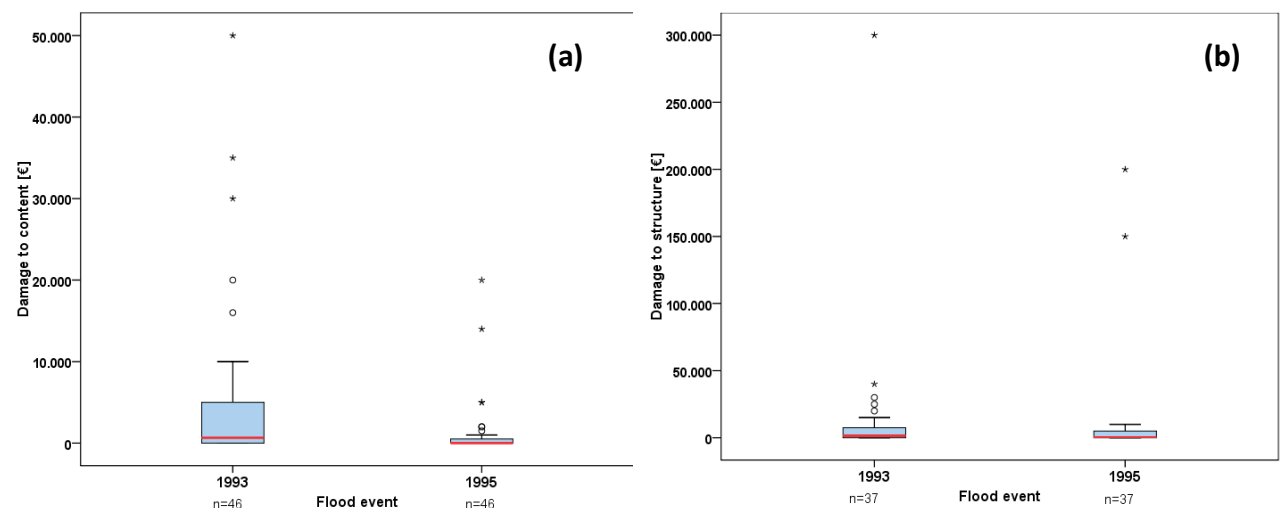

Fig. 3. Box whisker plots of (a) damage to contents and (b) damage to structure of respondents with close to identical water levels in the cellar and ground floor in 1993 and 1995. Note: Damage to contents and structure is significantly different (Wilcoxon signed-rank test) at the 1 per cent level.

event $\left(\right.$ mean $^{\text {cellar }}=157 \mathrm{~cm} /$ mean $\left.^{\text {ground floor }}=39 \mathrm{~cm}\right)$, compared with $1995\left(\right.$ mean $^{\text {cellar }}=147 \mathrm{~cm} /$ mean $^{\text {ground floor }}=$ $34 \mathrm{~cm}$ ). The Wilcoxon signed-rank test confirms that water levels were slightly lower in the cellar $(z=-4.806, p<$ $0.001, r=-0.28)$ and ground floor $(z=-4.774, p<0.001$, $r=-0.27)$ in 1995 at statistically significant levels $(p<$ 0.001 ). Whether respondents experienced slightly lower water levels in 1995, as such, or, whether these lower water levels resulted from an improved preparedness of the population, cannot be entirely established. However, the fact that the number of deployed flood barriers more than doubled within this sub-sample after 1993, and that the 1995 flood generally showed slightly higher overall water levels in many places, is a strong indication that lower water levels are a result of improved preparedness.

However, since inundation depth (water level) has been identified as a dominant factor of influence on flood damage (Thieken, 2005), the fact that households suffered less damage in 1995 than in 1993 could possibly also be due to lower water levels individually experienced by the surveyed households in 1995.

To examine whether the lower damage in 1995 is solely caused by differences in water levels individually experienced by the surveyed households during the two events, the same analysis was repeated with a final sub-sample $(n=62)$. The latter consisted only of those respondents who were affected both in 1993 and 1995 and, in addition, who reported close to identical water levels in the cellar and ground floor for the two events. The selection criterion was that water levels in the cellar and ground floor did not differ by more than $5 \mathrm{~cm}$ between the 1993 and 1995 event. The $5 \mathrm{~cm}$ selection criterion was chosen, as it is considered to be within the bounds of possible measurement or estimation errors of the respondents. By comparing damage to contents and structure for this final sub-sample, possible variations in reported damage can no longer result from differences in water levels. The results of this analysis are depicted in Fig. 3a and b.
As can be seen from Fig. 3a and b, damage to contents and structure still differs considerably between the 1993 and 1995 events, even though water levels are identical for both events. For this analysis the median damage for both contents and structure are also higher in 1993 (median $^{\text {contents }}=$ $1000 /$ median $\left.^{\text {structure }}=1000\right)$ than in $1995\left(\right.$ median $^{\text {contents }}=$ $0 /$ median $^{\text {structure }}=500$ ). The upper limits of the upper quartiles, the inter quartile range and the lower quartiles are also higher for 1993. Moreover, damage in 1993 shows a much larger variation. In conclusion, Fig. 3a and b show that households with identical water levels in 1993 and 1995 suffered considerably more flood damage to contents and structure in 1993 than in 1995. The Wilcoxon signed-rank test confirms that damage to contents $(z=-4.186, p<0.001, r=-0.44)$ and structure $(z=-2.77, p<0.01, r=-0.33)$ was lower in 1995 at statistically significant levels.

Since the number of implemented measures considerably increased between 1993 and 1995 for this final sub-sample as well, our findings strongly indicate that this damage reduction indeed resulted from an improved preparedness of the population. In total, the number of flood mitigation measures nearly doubled from 84 before the 1993 event to 159 before the 1995 flood for this final sub-sample. The effectiveness of flood mitigation measures is further supported by the fact that flood duration was generally slightly longer in 1995. This should have resulted in higher damage in 1995 , had flood preparedness not increased, because flood duration has also been found to increase the extent of flood damage suffered (Thieken, 2005).

To examine the damage-reducing effect of flood mitigation measures in 1995 in greater detail, four groups of respondents with different mitigation behaviours were compared with each other in terms of damage to contents and structures by means of the Wilcoxon signed-rank tests (Table 4). Based on the finding that the differences in damage between 1993 and 1995 are not due to differences in water levels (Fig. 3a and b), and due to restriction in sample size, 
these analyses were again carried out using the initial sample of 160 respondents (Fig. 2a and b). The four groups consisted of respondents that (a) had no measure implemented in 1993 and 1995, (b) had one or several measures in place in 1993 and did not undertake an additional type of measure before 1995, (c) had at least one measure in place in 1993 and undertook an additional type of measure before 1995, or, (d) overall increased the level of implemented measures, and, (e) had no flood mitigation measures in place in 1993 but did so in 1995.

The results of this analyses show that the largest damagereducing effect $\left(r^{\text {contents }}=-0.46 / r^{\text {structure }}=-0.5\right)$ was experienced by group (e), which was unprotected during 1993 (no measure) and undertook measure(s) before 1995, followed by the groups (c and d) that increased the level of preparedness $\left(r^{\text {contents }}=-0.44 / r^{\text {structure }}=-0.3\right)$. A lower damage-reducing effect in terms of contents was observed for group (b) that had measure(s) in place in 1993 but no additional type of measure in $1995\left(^{\text {contents }}=-0.38\right)$. No damage-reducing effect at statistically significant levels was found for this group in terms of damage to structure. The least damage-reducing effect was experienced by group (a) that had no measure in place both in 1993 and $1995\left(r^{\text {contents }}=-0.31 / r^{\text {structure }}=-0.26\right)$. The fact that the groups of respondents who increased the level of precaution (c, $\mathrm{d}$ and e) experienced the largest damage-reducing effect during the 1995 flood confirms the contribution of flood mitigation measures to damage reduction (Table 4).

However, the finding that the groups without an increase in precaution (groups a and b) also suffered lower damage in 1995 indicates that factors other than self-protection contributed to lower damage in 1995. It can be assumed that a learning effect also occurred at governmental agencies, resulting in a better catastrophe management, as it has been observed in other contexts (Kreibich and Thieken, 2009). An additional known factor that led to an overall reduction in damage in 1995 was the significantly lower contamination of flood waters, which again relates to the precautionary behaviour of flood-prone households. Contamination of flood water leads to considerably higher flood damage (Kreibich et al., 2011a), and, among several sources of contamination, the highest damage increase was being observed for oil contamination (Thieken, 2005). Contents and structures affected by oil-contaminated waters often need to be replaced or undergo costly renovations in the aftermath of a flood, instead of simply being cleaned-up. The ICPR (2002) reports that for a community at the Danube for a flood in 1999, 70 per cent of overall flood damage to buildings was caused by oil contamination. Along the Rhine, many households and businesses had replaced their oil with gas heating, or had secured their oil tank to avoid contamination in the aftermath of the 1993 event. In the present sample, the number of households that had replaced the oil heating increased from 20 to 47 , and 20 more households had secured their oil tank in 1995 (Table 3). As a consequence, the number of oil spills was drastically lower in 1995. In Cologne, for instance, the number of oil spills dropped from 100 in 1993 to 6 in $1995^{8}$.This explains how households that undertook no flood mitigation measures themselves during either event, or did not increase the level of preparedness, still benefitted from the improved preparedness of others.

A possible limitation of our study results from the short timing between both flood events, which occurred within only 13 months. Therefore, it might be the case that part of the household assets were not immediately replaced by the surveyed households in the aftermath of the 1993 event, and could therefore no longer be damaged in 1995 . However, this effect cannot explain the observed reduction in damage to structures in 1995 compared with 1993, which can be solely attributed to improved preparedness, suggesting that a similar reason caused the decline in contents damage.

Moreover, our finding that flood damage in 1995 was substantially lower due to better preparedness of those at risk is supported by previous studies, which confirm that flood mitigation measures can effectively reduce damage (e.g. Olfert, 2008). Kreibich et al. (2005), for instance, surveyed 1248 flood-prone households along the Elbe and found that floodadapted building use, flood-adapted interior fitting and the installations of heating and electrical utilities in higher storeys reduced the mean damage ratio for buildings by $46 \%, 53 \%$ and $36 \%$, respectively. Flood-adapted use and flood-adapted interior fitting could reduce the mean damage ratio for contents by $48 \%$ and $53 \%$, respectively.

\section{Conclusions}

Even though the contribution of private households to flood damage reduction by means of mitigation measures has become an integral component of contemporary flood risk management in Germany and many other countries, knowledge about the latter is still scarce. In the present paper, we examined the long-term development, the current implementation level and effectiveness of such private precautionary measures among private households along the Rhine to assess the efficiency of contemporary integrated flood risk management.

We found that different types of precautionary measures gradually increased between 1980 and 2011. A significantly increased rate of implementation can be consistently observed in the aftermath of severe flood disasters, especially after the 1993 flood event. As far as the current level of flood preparedness is concerned, we find that 56 per cent of the home owners and 36 per cent of the tenants implemented at least one flood mitigation measure. Given the fact that the vast majority of respondents come from highly flood-prone areas, it is noteworthy that a large share of households did not undertake a single precautionary measure. Lack of knowledge and lack of support for the increased responsibility of

\footnotetext{
8 http://undine.bafg.de/servlet/is/13880/
} 
Table 4. Damage-reducing effect of flood mitigation measures for respondents with different flood mitigation behaviour.

\begin{tabular}{lrr}
\hline \multirow{2}{*}{ Types of mitigation behaviour } & \multicolumn{2}{c}{ Damage-reducing effect r-value } \\
\cline { 2 - 3 } & contents & structures \\
\hline (a) No measures in 1993 and 1995 & $-0.31^{* *}(n=59)$ & $-0.26^{*}(n=65)$ \\
(b) No increase in measures & $-0.38^{*}(n=33)$ & n.s. $(n=30)$ \\
(c) Measure in 1993 and increase in 1995 & $-0.43 *(n=13)$ & n.s. $(n=11)$ \\
(d) Overall increase in measures between 1993 and 1995 & $-0.44^{* * *}(n=32)$ & $-0.30^{*}(n=28)$ \\
(e) No measure in 1993/Measure(s) in 1995 & $-0.46^{*}(n=19)$ & $-0.5^{*}(n=17)$ \\
\hline
\end{tabular}

* p-value $<0.05, * *$ p-value $<0.01, * * *$ p-value 0.001 level.

private households to contribute to flood damage reduction in contemporary flood risk management are identified as possible explanations for this low implementation level. Other factors that were found to influence flood mitigation behaviour are flood-coping appraisals, the social environment and nonprotective responses.

To examine the damage-reducing effect of flood mitigation measures, we compared the precautionary behaviour and damage suffered of households that were affected by two severe floods in 1993 and 1995. Our comparison demonstrates that the substantial damage reduction in 1995 can indeed be attributed to an improved preparedness of the flood-prone population. Moreover, we find that even respondents who did not undertake any precautionary measure themselves in 1993 and 1995 still benefitted from the improved preparedness of others due to lower levels of contaminated flood waters.

Our findings have important implications for contemporary integrated flood risk management. According to the projected effects of climate change, floods will become more frequent and more extreme in several regions, as well as along the Rhine in the coming decades (te Linde et al., 2010). This could imply that floods will increasingly affect areas with little prior flood experience. Given our findings that actual flood experience strongly influences the implementation level of mitigation measures, this also implies that highly vulnerable areas will be affected.

Therefore, if flood mitigation measures are indeed to provide an important contribution to contemporary integrated flood risk management, further efforts are required to reach a higher level of implementation among households at risk of flooding. For instance, flood insurance policies that are specifically designed to stimulate flood mitigation measures by rewarding precautionary behaviour with premium reductions, could be a promising way forward (Botzen et al., 2009; Holub and Fuchs, 2009; Aerts and Botzen, 2011). Currently, the potential to use insurance policies to stimulate precautionary behaviour of flood prone households remains unexploited by German insurers.

However, to reach the required level of preparedness even in areas with little prior flood experience, stricter legal regulations seem unavoidable. These regulations should not only apply to current flood zones (e.g. the $1 / 100 \mathrm{yr}$ flood zone) but should anticipate the effects of climate change on these flood zones. That it can be a rewarding undertaking to increase the level of flood mitigation measures at the household level is demonstrated by our finding that an adequate preparedness by private households can considerable contribute to damage reduction.

Acknowledgements. The authors would like to thank Adrian Schmid-Breton from the International Commission for the Protection of the Rhine (ICPR) for the fruitful discussions on the long-term implementation of flood mitigation measures. This research was carried out in the framework of the Dutch National Research Programme "Knowledge for Climate" (Assessment of upstream flood risk in the Rhine Basin (HSGR02) and Climate Proof Flood Risk Management) and has been co-funded by The Netherlands Organization for Scientific Research (NWO). The valuable comments provided by the two referees Sven Fuchs and Margreth Keiler are greatly acknowledged.

The service charges for this open access publication have been covered by a Research Centre of the Helmholtz Association.

Edited by: R. Schwarze

Reviewed by: S. Fuchs and M. Keiler

\section{References}

Aerts, J. C. J. H. and Botzen, W. J. W.: Climate change impacts on pricing long-term flood insurance: A comprehensive study for the Netherlands, Global Environ. Chang., 21, 1045-1060, doi:10.1016/j.gloenvcha.2011.04.005, 2011.

BFG: Hochwasser an Rhein und Mosel - Januar/Februar 1995; Luftbilderfassung durch das Aufklärungsgeschwader 51 der Bundeswehr in Jagel (Schleswig-Holstein), Bundesanstalt für Gewässerkunde, Koblenz, 1995.

Botzen, W. J. W., Aerts, J. C. J. H., and van den Bergh, J. C. J. M.: Willingness of homeowners to mitigate climate risk through insurance, Ecol. Econom., 68, 2265-2277, 2009.

Bouwer, L. M., Bubeck, P., and Aerts, J.: Changes in future flood risk due to climate and development in a Dutch polder area, Global Environ. Chang., 20, 463-471, doi:10.1016/j.gloenvcha.2010.04.002, 2010. 
Bubeck, P., Kreibich, H., Penning-Rowsell, E., Klijn, F., and De Moel, H.: Explaining differences in flood management approaches in Europe and the USA - A comparative analysis, in: Comprehensive flood risk management, edited by: Klijn, $\mathrm{F}$ and Schweckendiek, T., Research for policy and practice, Proceedings of the FLOODrisk2012 conference, November 2012, CRC press, Rotterdam, 2012a.

Bubeck, P., Botzen, W. J. W., and Aerts, J. C. J. H.: Detailed insights into the influence of flood-coping appraisals on mitigation behaviour, Global Environ. Chang., in review, 2012b.

Bubeck, P., Botzen, W. J. W., and Aerts, J. C. J. H.: A Review of Risk Perceptions and Other Factors that Influence Flood Mitigation Behavior, Risk Anal., 32, 1481-1495, doi:10.1111/j.15396924.2011.01783.x, 2012c.

Chbab, E. H.: How extreme were the 1995 flood waves on the rivers Rhine and Meuse?, Phys. Chem. Earth, 20, 455-458, doi:10.1016/s0079-1946(96)00005-5, 1995.

Cohen, J.: A power primer, Psychological Bulletin, 112, 155-159, 1994.

Engel, H.: The flood events of 1993/1994 and 1995 in the Rhine River basin, in: Destructive Water: Water-caused Natural Disasters, their Abatement and Control, IAHS Publication no. 239, edited by: Leavesly, G. H., Lins, H. F., Nobilis, F., Parker, R. S., Schneider, V. R., and Van der Ven, F. H. M., IAHS Press, Wallingford, UK, 1997.

Federal Environment Agency: Water Resource Management in Germany, Umweltbundesamt, Dessau-Roßlau, 2010.

Festinger, L.: A theory of cognitive dissonance, Stanford University Press, Stanford, 1957.

Few, R.: Flooding, vulnerability and coping strategies: local responses to a global threat, Prog. Develop. Studies, 3, 43-58, 2003.

Field, A.: Discovering Statistics Using SPSS, 3rd Edn., London, 2009.

Grothmann, T. and Reusswig, F.: People at risk of flooding: Why some residents take precautionary action while others do not, Nat. Hazards, 38, 101-120, doi:10.1007/s11069-005-8604-6, 2006.

Hall, J. W., Sayers, P. B., and Dawson, R. J.: National-scale assessment of current and future flood risk in England and Wales, Nat. Hazards, 36, 147-164, 2005.

Holub, M. and Fuchs, S.: Benefits of local structural protection to mitigate torrent-related hazards, in: Risk analysis VI, WIT transactions on information and communication technologies, edited by: Brebbia, C, and Beriatos, E., 39, WIT, Southampton, 401411, 2008.

Holub, M. and Fuchs, S.: Mitigating mountain hazards in Austria - legislation, risk transfer, and awareness building, Nat. Hazards Earth Syst. Sci., 9, 523-537, doi:10.5194/nhess-9-5232009, 2009.

Holub, M., Suda, J., and Fuchs, S.: Mountain hazards: Reducing vulnerability by adapted building design, Environ. Earth. Sci., 66, 1853-1870, 2012.

ICPR: Atlas of flood danger and potential damage due to extreme floods of the Rhine, International Commission for the Protection of the Rhine, Koblenz, 2001.

ICPR: Non structural flood plain management. Measures and their effectiveness, International Commission for the Protection of the Rhine, Koblenz, 2002.
ICPR: Umsetzung des Aktionsplans Hochwasser - Bericht 2005, International Commission for the Protection of the Rhine, Koblenz, 2005.

ICPR: Nachweis der Wirksamkeit von Massnahmen zur Minderung der Hochwasserstaende im Rhein infolge Umsetzung des Aktionsplans Hochwasser bis 2005, International Comission for the Protection of the Rhine, Koblenz, 2006.

ICPR: The rhine: A river and its relations, International Comission for the Protection of the Rhine, Koblenz, 2008.

John, P.: Analysing Public Policy, Continuum, London and New York, 1998.

Kreibich, H. and Thieken, A. H.: Coping with floods in the city of Dresden, Germany, Nat. Hazards, 51, 423-436, 2009.

Kreibich, H., Thieken, A. H., Petrow, Th., Müller, M., and Merz, B.: Flood loss reduction of private households due to building precautionary measures - lessons learned from the Elbe flood in August 2002, Nat. Hazards Earth Syst. Sci., 5, 117-126, doi:10.5194/nhess-5-117-2005, 2005.

Kreibich, H., Christenberger, S., and Schwarze, R.: Economic motivation of households to undertake private precautionary measures against floods, Nat. Hazards Earth Syst. Sci., 11, 309-321, doi:10.5194/nhess-11-309-2011, 2011a.

Kreibich, H., Seifert, I., Thieken, A. H., Lindquist, E., Wagner, K., and Merz, B.: Recent changes in flood preparedness of private households and businesses in Germany, Reg. Environ. Change, 11, 59-71, 2011b.

Kron, W.: Zunehmende Überschwemmungsschäden: Eine Gefahr für die Versicherungswirtschaft?, ATV-DVWK, Bundestagung 15-16 September 2004 in Würzburg, Germany, 2004.

Kron, W. and Thumerer, T.: Water-related disasters: Loss trends and possible countermeasures from a (re-)insurers point of view, Germany, 2002,

Laska, S. B.: Involving Homeowners in Flood Mitigation, J. Am. Plan. Assoc., 52, 452-466, 1986.

Olfert, A. and Schanze, J.: New approaches to ex-post evaluation of risk reduction measures: The example of flood proofing in Dresden, Germany, in: Flood Risk Management: Research and Practice, edited by: Samuels, P., Huntington, S., Allsop, W., and Harrop, J., London, Taylor \& Francis Group, 2008.

Petrow, T., Thieken, A. H., Kreibich, H., Bahlburg, C. H., and Merz, B.: Improvements on flood alleviation in Germany: Lessons learned from the Elbe flood in August 2002, Environ. Manage., 38, 717-732, 2006.

Rogers R. W. and Prentice-Dunn, S.: Protection motivation theory, in: Handbook of Health Behavior Research I: Personal and Social Determinants, edited by: Gochman, D. S., Plenum Press, New York, 113-132, 1997.

te Linde, A. H., Aerts, J. C. J. H., Bakker, A. M. R., and Kwadijk, J. C. J.: Simulating low-probability peak discharges for the Rhine basin using resampled climate modeling data, Water Resour. Res., 46, W03512, 2010.

te Linde, A. H.: Rhine at Risk? Impact of Climate Change on LowProbability Floods in the Rhine Basin and the Effectiveness of flood Management Measures, PhD, VU University, Amsterdam, 2011.

te Linde, A. H., Bubeck, P., Dekkers, J. E. C., de Moel, H., and Aerts, J. C. J. H.: Future flood risk estimates along the river Rhine, Nat. Hazards Earth Syst. Sci., 11, 459-473, doi:10.5194/nhess-11-459-2011, 2011. 
Thieken, A. H., Müller, M., Kreibich, H., and Merz, B.: Flood damage and influencing factors: New insights from the August 2002 flood in Germany, Water Resour. Res., 41, W12430, doi:10.1029/2005WR004177, 2005.

Thieken, A. H., Petrow, T., Kreibich, H., and Merz, B.: Insurability and mitigation of flood losses in private households in Germany, Risk Anal., 26, 383-395, 2006.

Thieken, A. H., Kreibich, H., Muller, M., and Merz, B.: Coping with floods: preparedness, response and recovery of flood-affected residents in Germany in 2002, Hydrol. Sci. J., 52, 1016-1037, 2007.
Wasserhaushaltsgesetz: Gesetz zur Ordnung des Wasserhaushalts (WHG), 2009.

Weinstein, N. D.: Effects of Personal-Experience on Self-Protective Behavior, Psychol. Bull., 105, 31-50, 1989.

Wilcoxon, F.: Individual Comparisons by Ranking Methods, Biometrics Bull., 1, 80-83, 1945.

Wind, H. G., Nierop, T. M., de Blois, C. J., and de Kok, J. L.: Analysis of flood damages from the 1993 and 1995 Meuse floods, Water Resour. Res., 35, 3459-3465, 1999. 